\title{
EL JUICIO DE PONDERACIÓN EN EL PROCEDIMIENTO DE TUTELA LABORAL
}

\author{
Francisco Alberto Ruay SÁEZ \\ Universidad de Chile
}

\begin{abstract}
RESUMEN: En el presente trabajo, el autor plantea una postura crítica sobre la inclusión del juicio ponderación de Robert Alexy como método idóneo para resolver los casos de colisión de derechos fundamentales en el procedimiento de Tutela Laboral. Para cumplir dicho objetivo se analiza la estructura interna del principio de proporcionalidad; los subprincipios de adecuación, necesidad y proporcionalidad en sentido estricto.
\end{abstract}

Palabras clave: Juicio de ponderación, derechos fundamentales, Tutela Laboral, principio de proporcionalidad.

ABSTRACT: In this paper the author proposes a critical position about the incorporation of the Robert Alexy balancing test like a suitable method to solve the cases of collision of fundamental rights in the procedure of Labor Guardianship. To achieve this aim the author analyzes the internal structure of the proportionality principle; the sub-principles of adequacy, necessity and proportionality in stricto sensu.

Key words: Judgment of weighting, fundamental rights, Labor Guardianship, proportionality principle.

\section{INTRODUCCIÓN}

Se sostiene por la doctrina, que el procedimiento de Tutela Laboral supone la idea de eficacia horizontal de los derechos fundamentales (teoría de la Drittwirkung der Grundechte), y además, una noción conflictualista de los $\operatorname{mismos}^{1}$, como manifestaciones positivas de la Constitucionalización del Derecho del Trabajo ${ }^{2}$. En dicho procedimiento se le encarga una tarea compleja al juez: resolver las colisiones de derechos fundamentales, que se susciten en el contexto de la relación laboral, entre empleador y trabajador, producto de las medidas que emanen del primero en el ejercicio de su poder de dirección. Nuestra dogmática jurídica recoge el principio de proporcionalidad (en sentido amplio) formulado por Robert Alexy como método racional idóneo para resolver dichas colisiones.

En las siguientes páginas pretendo exponer la estructura del principio de proporcionalidad (también llamado método de ponderación) de manera crítica, y mostrar por qué su inserción en el procedimiento de Tutela Laboral, más propiamente en la argumentación

\footnotetext{
* Estudiante de Derecho de la Universidad de Chile. Ayudante Ad honorem de la cátedra de Derecho del Trabajo.

1 Ugarte Cataldo, José Luis. El Nuevo Derecho del Trabajo. Santiago, Chile: Editorial LexisNexis, 2007, pp. 114 y ss. GAMONAL CONTRERAS, Sergio. Ciudadanía en la empresa o los derechos fundamentales inespecíficos. Montevideo, Uruguay: FCU, 2004, pp. 13 y ss., entre otros.

2 "Este procedimiento de tutela viene a ser la traducción procesal de la idea de eficacia horizontal de ese tipo de derechos en las relaciones jurídicas entre privados, y en este particular caso al interior del contrato de trabajo”. UGARTE CATALDO, José Luis. "La constitucionalización del derecho del trabajo: la tutela de derechos fundamentales", en: Revista Latinoamericana de Derecho Social No 7, julio-diciembre, p. 265. México: Instituto de Investigaciones Jurídicas, Universidad Nacional Autónoma de México, 2008.
} 
jurídica que desarrolle el juez en la resolución del caso, significa un desmedro para la certeza jurídica, con falsa apariencia de racionalidad mecánica.

\section{EL PRINCIPIO DE PROPORCIONALIDAD DE ROBERT ALEXY}

\subsection{DISTINCIÓN FUERTE ENTRE PRINCIPIOS Y REGLAS}

La distinción básica, y que sirve de fundamento 3 para construir teóricamente el juicio de ponderación como forma de solución de conflictos de derechos fundamentales, es aquella que diferencia entre principios y reglas, como dos tipos de normas diferentes: "[...] toda norma o bien es una regla o un principio" ", "[l] as reglas son normas que, dadas determinadas condiciones, ordenan, prohíben, permiten u otorgan un poder de manera definitiva. Así, pueden caracterizarse como "mandatos definitivos"; completamente distinto [...] son normas que ordenan que algo debe hacerse en la mayor medida fáctica y jurídicamente posible. Las posibilidades jurídicas, además de depender de reglas, están esencialmente determinadas por otros principios opuestos, hecho que implica que los principios pueden y deben ser ponderados. Los derechos que se basan en principios son derechos prima facie" ", no derechos definitivos. Lo importante aquí es que "los derechos fundamentales tienen el carácter de principios y [...] que los principios son mandatos de optimización"7. Que tengan tal carácter implica que pueden ser cumplidos gradualmente, y no necesariamente que se busque un punto máximo de rendimiento de los derechos fundamentales en donde todos ganen (a pesar de que Alexy varias veces haga referencia al óptimo de pareto).

La distinción anteriormente expuesta (en un plano ontológico), tiene una expresión funcional importantísima: "a la distinción entre reglas y principios le corresponden dos tipos diferentes de aplicación de las normas: la subsunción y la ponderación" 8 . A lo anterior corresponde una diversa forma de resolver enfrentamientos de normas de uno u otro tipo: conflictos de reglas, por una parte, o la colisión de principios, por otro. Alexy señala que es "[c]omún a las colisiones de principios y a los conflictos de reglas [...] el hecho de que, dos normas aplicadas independientemente, conducen a resultados incompatibles" ${ }^{9}$, sin embargo los métodos de solución de enfrentamiento de normas serían diversos. Mientras que en las reglas el conflicto se soluciona declarando la invalidez de una de estas, o una cláusula de excepción, en el caso de los principios, por su parte, se aplica el juicio de ponderación lo

\footnotetext{
3 Alexy señala: "Para la teoría de los derechos fundamentales, la más importante es la distinción entre reglas y principios. Ella constituye la base de la fundamentación iusfundamental y es una clave para la solución de los problemas centrales de la dogmática de los derechos fundamentales. Sin ella no puede existir una teoría adecuada de los límites, ni una teoría satisfactoria de la colisión y tampoco una teoría suficiente acerca del papel que juegan los derechos fundamentales en el sistema jurídico". AleXY, Robert. Teoría de los derechos fundamentales. Madrid, España: Centro de Estudios Constitucionales, 1993, p. 81.

$4 \quad$ Ibid., p. 87

5 ALEXY, Robert. "Derechos, razonamiento jurídico y discurso racional", en: Isonomia: Revista de Teoría y Filosofía del Derecho No 21, octubre 1994, p. 41. Alicante, España: Universidad de Alicante.

6 Ibid., p. 41.

7 Alexy, Robert. "Epílogo a la Teoría de los Derechos Fundamentales" (trad. del alemán de Carlos Bernal Pulido) en: Revista española de Derecho Constitucional, Año 22, No 66, septiembre-diciembre 2002, p. 13.

8 AleXY, Robert. "Derechos, razonamiento... (n. 5), p. 44.

9 AleXY, Robert. “Teoría... (n. 1), p. 87.
} 
que Alexy denomina un "procedimiento racional de ponderación”, que pasaremos a exponer sintéticamente a continuación.

\subsection{LA ESTRUCTURA DE LA PONDERACIÓN}

Ya se ha reiterado innumerables veces en qué consiste el mencionado juicio de ponderación, o principio de proporcionalidad, sin embargo cabe aquí hacer una breve referencia para en su desarrollo ir evaluando cada una de las propuestas teóricas de Alexy .

Para resolver casos de colisión de derechos fundamentales ha de aplicarse, según Alexy, la aplicación del principio de proporcionalidad, producto de lo cual se logrará la determinación analítica de los pesos relativos de los derechos que se encuentren en disputa. Para llevar adelante esta tarea Alexy se ve obligado a negar que un juicio de ponderación solo esconde una mera decisión arbitraria irracional o intuición, y en su lugar, propone que es posible llevar adelante un procedimiento racional de ponderación, que se encuentre fundado y estructurado desde la teoría de los principios. Desde ahí señala que "los principios son mandatos de optimización [y] como tales, implican lo que en la doctrina alemana se llama la "regla de proporcionalidad". Esta regla comprende tres subreglas: la regla de la adecuación, la regla de necesidad y la regla de proporcionalidad en sentido estricto" 10 . El subprincipio de adecuación "excluye la adopción de medios que infrinjan un derecho constitucional sin promover ningún derecho u objetivo para los que se adoptaron tales medios"11; el subprincipio de necesidad prescribe que de entre dos medios que promueven idóneamente un mismo principio, ha de escogerse aquel que interfiera menos en el principio que se encuentra en colisión; y por último, el principio de proporcionalidad en sentido estricto (identificable con la ley de colisión) señala que "cuanto más alto sea el grado de incumplimiento o perjuicio de un principio, más importante tiene que ser la realización del otro" 12 .

Una versión completa del juicio de ponderación debe abarcar todos los elementos que Alexy considera relevantes en la resolución de colisiones de principios, y en ese sentido, sin olvidar obviamente la estructura general tripartita de subprincipios, se vuelve imperativo hacerse cargo de la estructura compleja de la ponderación en su última fase compuesta por: la ley de ponderación (o ley de colisión) ${ }^{13}$, la fórmula del peso y las cargas de argumentación ${ }^{14}$. Es sobre aquellos elementos que desarrollo el estudio.

\footnotetext{
10 AlEXY, Robert. "Derechos, razonamiento... (n. 5), p. 46. Cabe señalar que en otro lugar se les denomina subprincipios. ALEXY, Robert. "Derechos fundamentales, ponderación y racionalidad”, en: Revista Iberoamericana de Derecho Procesal Constitucional, enero-junio de 2009, p. 8. Disponible en: <http://www.iidpc.org/revistas/11/pdf/19_29.pdf> [Consultado 10 de noviembre de 2011].

11 ALEXY, Robert. "Sobre los derechos constitucionales a protección”. En: VV.AA. Derechos sociales y ponderación. Madrid, España: Fundación Coloquio Jurídico Europeo, 2009. p. 57.

12 AleXY, Robert. "Teoría... (n. 1), p. 146.

13 "La ponderación es objeto del tercer subprincipio del principio de proporcionalidad, el de proporcionalidad en sentido estricto; este subprincipio dice lo que significa la optimización relativa a las posibilidades jurídicas. Es idéntico a una regla que podemos denominar "ley de ponderación" la cual dice: Como alto sea el grado de incumplimiento o perjuicio de un principio, tanto tiene que ser la importancia de la realización del otro" ALEXY, Robert. "Derechos fundamentales... (n. 10), p. 9.

14 "De acuerdo con Alexy, para establecer la relación de precedencia condicionada entre los principios en colisión, es necesario tener en cuenta tres elementos que forman la estructura de la ponderación: la ley de ponderación, la fórmula del peso y las cargas de argumentación".
} 


\section{CONFLICTOS DE DERECHOS FUNDAMENTALES EN EL PROCEDIMIENTO DE TUTELA LABORAL}

\subsection{UN ACERCAMIENTO DESDE LA DOCTRINA NACIONAL}

El Derecho del Trabajo ha ampliado sus horizontes protectores, acogiendo la teoría de la eficacia horizontal de los derechos fundamentales, para insertarla directamente al interior de la empresa ${ }^{15}$. Se trataría de la entrada de la democracia a la empresa, la inserción del trabajador al ámbito laboral ya no solo como un factor de producción, sino como un ciudadano titular de derechos fundamentales, titular de un conjunto complejo de derechos ${ }^{16}$. Este fenómeno ha sido denominado bajo el concepto de ciudadanía en la empresa. Este reconocimiento de los derechos inespecíficos del trabajador al interior de la empresa, la idea de que la Constitución sería una fuente de derecho vinculante y directamente aplicable, es una expresión de lo que se ha denominado la "constitucionalización general del Derecho" ${ }^{17}$, susceptible de ser situada en las corrientes denominadas "neoconstitucionalistas"18.

BERnAl PUlido, Carlos. "La ponderación como procedimiento para interpretar los derechos fundamentales", en: CÁCERES, E.; Flores, I. B.; Saldaña J; y Villanueva, E. (coord.). Problemas contemporáneos de la filosofía del derecho. México: Universidad Nacional Autónoma de México, 2005, p. 21. Disponible en: <http://www.bibliojuridica.org/libros/4/1650/5.pdf> [Consultado 10 de noviembre de 2011].

15 Al respecto: "Lo interesante de todo es que el sector del ordenamiento jurídico donde este debate se difumina [el debate sobre la eplicabilidad de la eficacia horizontal de los derechos fundamentales] es, precisamente, en el derecho laboral. Aquí la lógica de la autonomía privada y de la igualdad de las partes, principal lanza argumentativa de los partidarios de la eficacia indirecta, viene trastrocada desde mucho antes de la constitucionalización del derecho -y de la eficacia horizontal de los derechos fundamentales-, en razón de haber intentado esta rama del derecho, desde su aparición histórica, la corrección y equilibrio de la situación de poder en que se desenvuelve la relación privada entre empleador y trabajador". UGARTE CATALDO, José Luis. "La constitucionalización... (n. 2), p. 259.

16 El profesor Ugarte realiza una distinción que permite clarificar mucho más las diversas dimensiones protectoras del Derecho del Trabajo, y así señala: "El Derecho del Trabajo ha cumplido y cumple así diversas funciones, de modo simultáneo, preocupado de la protección de los derechos de los trabajadores en diversos planos: 1. Los derechos laborales propiamente tales (salarios mínimos, jornada de trabajo, indemnizaciones por término de contrato), atribuidos al trabajador como contratante débil, que ha permitido asegurar un mínimo socialmente aceptable para los trabajadores, 2. Los derechos fundamentales específicos (libertad sindical, derecho negociación colectiva, huelga) atribuidos al trabajador como miembro de una organización de representación de intereses, que han permitido al Derecho del Trabajo intentar democratizar la dirección económica y política de las empresas y de algún modo de la propia sociedad, y por último 3. Los derechos fundamentales inespecíficos (intimidad, integridad, libertad de expresión, no discriminación), atribuidos al trabajador en su calidad de ciudadano, han permitido al Derecho del Trabajo garantizar al interior de las empresas un trato digno y acorde con un miembro de una sociedad democrática"]. UGARTE CATALDO, José Luis. "La tutela de derechos fundamentales y el derecho del trabajo: de erizo a zorro", en: Revista de Derecho, Vol. XX No 2, pp. 51-51. Valdivia, Chile: Universidad Austral de Chile, Facultad de Ciencias Jurídicas y Sociales, 2007.

17 "En este nuevo paradigma, la clave será considerar que las normas constitucionales tienen todas -sin distinción- plena eficacia vinculante, y que [...] son susceptibles de producir efectos jurídicos inmediatos, sin necesidad de mediación legal de ningún tipo". UGARTE CATALDO, José Luis. "La constitucionalización... (n. 2), p. 255.

18 Entre los fenómenos distintivos de las tendencias denominadas "neo" constitucionalistas, relevantes para el desarrollo de nuestro estudio se encuentra la idea de: "[...] c) constituciones con fuerza normativa vinculante y aplicación directa en el sistema de fuentes, con el consiguiente resultado de irradiación (de la constitución hacia las demás fuentes) y de "constitucionalización” del derecho, cuando los tribunales asumen ambos postulados; d) consideración de los derechos fundamentales y eventualmente de otras partes del texto constitucional como "valores" en la argumentación fundante de decisiones jurisdiccionales, en especial, pero no exclusivamente, a nivel de la jurisdicción constitucional; e) introducción del "método" de ponderación para la solución de conflictos entre derechos fundamentales o entre derechos fundamentales y otros principios constitucionales (en general, proposición de la ponderación como forma de solucionar la colisión entre valores). Al igual que en el literal 
El mencionado fenómeno fue recogido por la legislación laboral, y en consecuencia, se estableció un procedimiento especial ${ }^{19}$ para demandar vulneraciones de derechos fundamentales del trabajador por parte del empleador: el procedimiento de Tutela Laboral. En dicho procedimiento básicamente se daría solución a la colisión entre los derechos fundamentales del trabajador que se encuentran señalados en el artículo 485 del Código del Trabajo, y el derecho de fundamental que el empleador considere a su favor como fundamento de la medida que adopte, que en la mayoría de los casos corresponderá al derecho de propiedad.

Para determinar si las garantías y derechos de los trabajadores han sido lesionados, el mismo precepto señala los supuestos en que la acción del empleador en el ejercicio de las facultades que la ley le reconoce ha llegado a ser vulneratoria: cuando limita el pleno ejercicio de las garantías del subordinado sin justificación suficiente, en forma arbitraria o desproporcionada, o sin respeto a su contenido esencial, así como las eventuales represalias que el empleador pudiese adoptar a causa de la labor fiscalizadora de la Dirección del Trabajo o el ejercicio de acciones judiciales.

La cultura jurídica interna relacionada directamente con el derecho laboral ha acogido el método ponderativo de Robert Alexy como método jurídicamente idóneo para la solución de colisión de derechos fundamentales en sede laboral. Incluso, previo a la configuración del actual procedimiento de Tutela Laboral, la Dirección del Trabajo ya habría utilizado dicho criterio ${ }^{20}$.

José Luis Ugarte señala que "este conflicto de derechos fundamentales [entre el empleador y el trabajador] supone una modalidad de aplicación del derecho distinta al común o tradicional -la subsunción- que corresponde a la denominada ponderación" 21 . En un texto reciente vuelve a defender el método de ponderación, luego de asumir la inevitable posibilidad de colisión entre derechos fundamentales, y desechar el método de jerarquización cerrada y estática ${ }^{22}$. En el mismo sentido se pronuncia Sergio Gamonal, diferenciando la relaciones Estado-ciudadano y empleador-trabajador (particular-particular), pasando a sostener que "no es posible asimilar la eficacia vertical con la horizontal" 23 , y hace suyos los argumentos de Alexy sobre la diferenciación en un conflicto entre dos titulares de derechos fundamentales (dos ciudadanos comunes), y un titular de derechos fundamentales

precedente, en especial, pero no exclusivamente, a nivel de la jurisdicción constitucional [...]". ALDUNATE LiZANA, Eduardo. "Aproximación conceptual y crítica al neoconstitucionalismo"; en: Revista de Derecho, Vol. XXIII No 1, pp. 83-84.Valdivia, Chile: Universidad Austral de Chile, Facultad de Ciencias Jurídicas y Sociales, 2010.

19 Es discutible su calidad de procedimiento especial si en lo referente al desarrollo consecutivo de los actos procesales remite directamente al procedimiento de aplicación general. Sin perjuicio de aquello, se establecieron algunas reglas especiales en consideración de la naturaleza de la infracción que se produciría por el empleador y que lo distinguen el procedimiento de aplicación general. Es en esos elementos especiales en donde se genera la discusión, por ejemplo, sobre las cargas probatorias dinámicas, sobre el alcance de las medidas reparatorias que puede decretar el juez, o la eventual aplicación del juicio de ponderación.

20 Gamonal Contreras, Sergio, "Ciudadanía... (n. 1), pp. 25 y ss. Dictámenes 684/50 DE 1997, 4.842/300 DE 1993; 8.273/337 DE 1995; 287/14 DE 1996; 2.309/165 DE 1998 y 4.541/319 de 1998, entre otros.

21 Ugarte Cataldo, José Luis, “El Nuevo Derecho... (n. 1), p. 145.

22 Ugarte Cataldo, José Luis. "Privacidad, trabajo y derechos fundamentales", en: Estudios Constitucionales, Año 9, № 1, pp. 22-26. Talca, Chile: Centro de Estudios Constitucionales de Chile Universidad de Talca, 2001.

23 Gamonal Contreras, Sergio, "Ciudadanía... (n. 1), pp. 23. 
y otro que no lo es (el Estado), "lo que nos lleva al tema de la ponderación"24. A su vez, Eduardo Caamaño adhiere a esta postura cuando expresa que: "[...] en el ejercicio de un derecho fundamental puede producirse un conflicto con otros derechos o bienes constitucionalmente protegidos, el que se ha de resolver mediante la utilización de mecanismos de ponderación en clave constitucional" 25 . Incluso el profesor Gamonal ha llegado a identificar parte del texto normativo contenido en el art. 485 CT con los elementos de la ponderación propuestos por Alexy ${ }^{26}$.

\subsection{ANÁLISIS CRÍTICO DE LA PONDERACIÓN}

Analizaré, uno por uno, los tres subprincipios del principio de proporcionalidad o juicio de ponderación, y la posibilidad de obtener un resultado positivo (un juicio racional) de su utilización. Luego, también revisaré la estructura de la ponderación, que permite establecer qué principio en el caso concreto tendrá mayor peso, luego de haber analizado las posibilidades fácticas de la medida en cuestión. A medida que vaya avanzando presentaré las consecuencias que acarrea la aplicación del juicio de ponderación como método de solución de colisión de derechos fundamentales, en especial, en el procedimiento de Tutela Laboral.

Intentaré no caer en reiteraciones o redundancia conceptuales, aunque a ratos será necesario volver sobre algunos conceptos para plantear mis ideas de manera más clara.

\subsubsection{El subprincipio de adecuación}

García Amado en un interesante artículo realiza una evaluación crítica del principio de proporcionalidad. En dicho texto, y en relación al subprincipio de adecuación o idoneidad, postula categóricamente que: "el principio de idoneidad solo opera, y opera bien, cuando se ha predecidido entre qué dos derechos o principios tiene lugar el conflicto que en el caso se dirime. $\mathrm{Y}$ es tal predecisión la que predetermina el resultado final de la aplicación del principio de idoneidad" 27 . En otras palabras, el resultado del análisis de adecuación de una medida cualquiera que limite un derecho fundamental P estará ya condicionado, y en gran

\footnotetext{
24 Ibid.

25 CAAMAÑo Rojo, Eduardo. "La ley de subcontratación y la tutela de los derechos fundamentales de los trabajadores de servicios transitorios”, en: Ius et Praxis, vol. 13, No 2, p. 182. Talca, Chile: Universidad de Talca, Facultad de Ciencias Jurídicas y Sociales, 2007.

26 El profesor Gamonal desarrolla un cuadro que reflejaría la dirección directa entre el método expuesto por Alexy y las normas contenidas en el artículo 485 CT. Así, la expresión "justificación suficiente" tendría relación directa con la subregla de "necesidad", que la medida no sea arbitraria tiene una correlación directa con la regla de adecuación, el requisito que exige que "la medida no sea desproporcionada", encuentra su correlato en el análisis de la proporcionalidad en sentido estricto, en una faz que mira hacia la racionalidad del objeto en la medida adoptada, el que "no debe afectarse el contenido esencial del derecho", tendría su correspondencia directa con la proporcionalidad en sentido estricto desde la faz de los efectos de la medida, y por último, el que "no debe tratarse de una represalia", es expresión de la subregla de proporcionalidad en sentido estricto desde el punto de vista de los efectos de la medida. En ese sentido, la garantía de indemnidad servirá como criterio definitorio posterior a los anteriormente señalados y tendrá el carácter de absoluto, ya que no se comportaría al igual que las otras garantías, pues pareciere que no es posible graduar la intención de represalia que puede tener el empleador, como si hubiese un margen de represalia permitido o lícito, y un límite que definiera la vulneración o no. Gamonal ConTreras, Sergio. Procedimiento de Tutela de derechos Laborales. Santiago, Chile: Editorial LexisNexis, 2007, p. 37.

27 García Dalmado, Juan Antonio. "El juicio de ponderación y sus partes. Una crítica”. En: VVAA. Derechos sociales y ponderación. Madrid, España: Fundación Coloquio Europeo, 2007, p. 249.
} 
parte resuelto, por la decisión sobre el principio que se escoge como beneficiario de tal limitación. En tal sentido, el aspecto esencial de la argumentación del tribunal correspondiente quedará oculto en la selección del principio (Px) que se enfrente a P. Así, se predicará de una medida cualquiera que es idónea, asumiendo previamente cuál será el principio que se someterá a análisis, a fin de verificar si existe para aquel alguna ventaja como consecuencia de la medida en cuestión. Dicho ejercicio supone descartar otras vías de análisis posible, es decir, la posibilidad de que sean otros los principios beneficiados que entren en conflicto con P. Sobre este punto se puede realizar un análisis meramente fáctico (puesto que las posibilidades de realización de la medida se evalúan en su dimensión fáctica mediante la aplicación del subprincipio de adecuación y el de necesidad), pero parece que no es tan simple.

Ahora, ¿por qué elegir uno u otro principio (dentro de todos los posibles Px) como fundamento de la limitación de P? Aquello es simplemente el resultado de la interpretación de la medida decretada. Lo relevante es que no siempre el juez que esté aplicando la Constitución expondrá como parte de la argumentación jurídica interna las razones por las que desecha algunos principios y no otros. Pero inclusive, en caso de que sí se refiera a tal decisión en la sentencia, lo que sucederá es que lo decisivo en la argumentación jurídica ya no será la aplicación casi mecánica del subprincipio de adecuación, sino más bien, el ejercicio hermenéutico que le lleva a concluir que es un determinado principio el que entra en conflicto con $\mathrm{P}$, y no otro, e inmediatamente el problema jurídico se traslada desde el método ponderativo (supuestamente objetivo y racional en el balanceo de los principios) a un paso previo; la interpretación de la medida adoptada (o texto normativo si existiese). La ponderación, de entrada, pasa a situarse en un segundo plano, o a lo más, como un paso final del trabajo interpretativo de sobre la medida en cuestión y los derechos en conflicto. Un juicio que se presenta prácticamente como mecánico (decidir si una medida es idónea o no), es en el fondo sumamente complejo, o por lo menos ha de concederse, que no es tan simple como se presenta ${ }^{28}$.

En el ámbito de las relaciones laborales básicamente se ha señalado la posibilidad de conflicto entre el derecho de propiedad del empleador, manifestado en su potestad de dirección y mando, por un lado, y los derechos fundamentales de los que es titular el trabajador, enumerados taxativamente en la ley. Pareciese que por esta razón ya se encuentra solucionado uno de los elementos que hace criticable el subprincipio de adecuación. Esto, debido a que por la propia naturaleza de la relación laboral ya se encuentra "objetivamente" determinado al menos uno de los derechos fundamentales que colisionan: el derecho de propiedad del empleador. Sin embargo, dicha consideración no es del todo pacífica, aunque aparece como evidente. Alexy no supone, en el uso de su método, que la medida sujeta a evaluación bajo el principio de proporcionalidad deba necesariamente beneficiar un derecho fundamental de quién dicta la medida. Aquello es obvio, porque Alexy piensa más en las medidas que son de fuente Estatal; con efectos interprivados, pero eminentemente como un estándar de control de las medidas adoptadas por el Estado que pudiesen acarrear efectos negativos para los privados. Si es que alguna utilidad tuviese la aplicación del principio

28 "El juicio de ponderación es totalmente tributario de la previa interpretación de la norma cuestionada, y ello en un doble sentido: i) tributario del fin que, de entre los posibles, se asigne en concreto a la norma; y ii) tributario de la prospección o cálculo que se haga de las consecuencias que la aplicación de la norma puede tener en relación con ese fin”. Ibid., p. 270. 
de proporcionalidad, sería más bien en relación con el control de las decisiones legislativas que tengan efectos entre privados, que en una decisión adoptada por un particular frente a otro. Esto sería salvable desde la idea que la relación laboral, y en particular, la esfera de convivencia de la empresa, respecto de cualquier otra relación entre privados, tendría como elemento constituyente la relación de subordinación, y el ejercicio de un "poder" por parte del empleador, y con ello, podría afirmarse que así como podrían someterse a evaluación las medidas adoptadas por el Estado a través del Poder Legislativo, también deberían someterse al principio de proporcionalidad las medidas adoptadas por el empleador, en el ejercicio de su poder de mando sobre los trabajadores. Aun concediendo lo señalado, no se profundiza sobre cuáles serían los posibles fundamentos del ejercicio de tal poder. En concreto: ¿podría el empleador justificar la idoneidad de su medida ya no solo en su derecho de propiedad ${ }^{29}$, sino que en el fundamento tener como beneficiario a un tercero, que incluso puede tratarse de otro grupo de trabajadores? Para evaluar esta posibilidad hay que pensar en un caso un tanto extraordinario, pero no imposible, más cercano a las concepciones corporativistas y comunitarias de la empresa, que al empresario típico, individualista y optimizador económico, que lo único que pretende es aumentar sus utilidades. Pensemos, por ejemplo, en que arrogándose una facultad en virtud de un fin legítimo de protección de la salud de sus trabajadores (Art. 90 CPR) dispone que todos sus empleados deban someterse a un examen médico, gratuito y dispuesto por el propio empleador obviamente, la última semana de cada mes. En este examen básicamente se medirá el índice de grasa, y se publicará en el diario mural de la correspondiente empresa la lista de quienes tengan problemas de sobrepeso, para que asistan a una rutina voluntaria de ejercicios dirigidos por un preparador físico en el gimnasio de la empresa, todo esto sin costo alguno para ellos. Sin duda habrá trabajadores que se sientan plenamente complacidos y alegres por esta preocupación, que manifiesta una forma de satisfacción de su derecho a la protección de la salud. Sin embargo otros, viéndose ofendidos, alegarán una vulneración a su intimidad e integridad síquica, al estar incitando al mobbing laboral con la publicación de datos que son íntimos (básicamente por la publicación de quienes están en sobrepeso). Para determinar si la medida es adecuada o no, podríamos ya no mirar al derecho de propiedad del empleador, sino a los beneficios que percibiría un grupo de trabajadores frente a otros, enfrentándose el derecho a la protección de la salud de algunos, contra la intimidad e integridad síquica de otros. El derecho de propiedad, eventualmente, podría dejarse a un lado en el análisis de este problema, más aún, si lo que se pretende es comparar el ejercicio de poder del Estado sobre los particulares, con el ejercicio de poder del empleador sobre los trabajadores. Dicha decisión dependerá de la interpretación que el juez haga sobre la medida y los derechos que colisionan aparentemente.

Por lo anteriormente señalado, la crítica realizada al principio de adecuación no es banal, y es procedente también aquí en sede laboral. Hay una decisión previa sobre la elección del derecho de propiedad para medir la legitimidad de la medida, lo que en la mayoría de los casos ha de ser acertado, más no hay profundización sobre la especial relación de poder entre empleador y trabajador, y hasta qué punto sería similar a la relación Estado-individuo

\footnotetext{
29 Al Estado no se le exige que justifique sus medidas en el beneficio de un principio propio, puesto que no es titular de derechos fundamentales; su legitimidad se fundaría en el principio democrático. En todo caso, su finalidad debe ser promover el bien común, por lo que es razonable que fundamente en aquella meta las medidas adoptadas.
} 
(dicho paralelo se realiza comúnmente con el fin de evitar las posibles críticas a la eficacia horizontal de los derechos fundamentales). Podría concederse incluso que el fundamento último de la medida que adopte el empleador es su derecho de propiedad, aunque en un segundo nivel se encuentre beneficiando derechos fundamentales de terceros, puesto que es ahí donde se sostendrían las potestades de dirección y mando. Sin embargo, no siempre coincide el titular del dominio sobre los medios de producción y la posición de empleador, lo que vuelve aún más compleja la distinción ${ }^{30}$.

Por otro lado, pensando en los casos corrientes, en que efectivamente sería el derecho de propiedad identificado como el principio vulnerador de algún derecho del trabajador, hay que desenmarañar en qué consistiría esa adecuación. En primer lugar, el derecho vulnerado viene determinado por el contenido de la demanda presentada por el legitimario activo en concreto (trabajador, organización sindical o Dirección del Trabajo), a menos que concibamos la posibilidad de que el juez agregue como vulnerado un derecho fundamental que no ha sido considerado por la parte demandante, caso en el cual retrocedemos a las críticas planteadas anteriormente sobre la determinación previa de los derechos que colisionan. Luego, la idoneidad de la medida, asumiendo que su finalidad en este caso es beneficiar el derecho de propiedad del empleador, estará básicamente determinada por el cálculo de las consecuencias de su aplicación en relación con el principio que pretende beneficiar. Aquel cálculo queda sujeto a la interpretación del derecho de propiedad que realice el juez respectivo, en relación a sus alcances y límites internos (si considera que los tiene), y como es evidente, no bastará con un análisis mecánico de la medida en relación con el derecho fundamental vulnerador. Si bien se trata de un ámbito fáctico de análisis, aquel no es meramente empírico natural, pues se realiza bajo un prisma jurídico del que no le es posible al juez escapar, y que sirve de fundamento al análisis de idoneidad, lo que nos lleva a afirmar que lo que en realidad se desarrolla, ya en este primer paso del juicio de ponderación, es una actividad interpretativa respecto de la medida (o texto normativo) y de los derechos fundamentales involucrados. Por lo tanto, la adecuación no está "afuera", puesta objetivamente frente al juez, esperando que él constate su presencia, sino que es él más bien quien debe desarrollar argumentativamente dicha correspondencia, desde sí, y sus conocimientos del derecho.

\subsubsection{El subprincipio de necesidad}

Hay que recordar que en el juicio de ponderación se utiliza el término necesidad no en referencia a la noción filosófica naturalista que entendería por tal concepto algo así como lo siguiente: se puede predicar de un fenómeno $\mathrm{X}$ que es necesario respecto de $\mathrm{Y}$, si y solo si, dado un fenómeno precedente $\mathrm{Y}$ no puede sino tener como consecuente a $\mathrm{X}$. O sea, no cabe una comprensión en este sentido; un juicio de necesidad que responde directamente a la idea de causalidad natural. Dicha noción está más relacionada con las comprensiones epistemológicas de los fenómenos que pudiesen incidir en la decisión (en la determinación

30 De hecho, en la definición de "empleador" contenida en el art. $3^{\circ} \mathrm{CT}$ en ningún momento se hace referencia a un derecho de propiedad como fundamento de su posición en la relación laboral. Simplemente se señala que: "es la persona natural o jurídica que utiliza los servicios intelectuales o materiales de una o más personas en virtud de un contrato de trabajo". Por lo tanto es posible que el empleador no sea propietario de los medios de producción de la empresa, y aún así sea parte de la relación laboral con el trabajador (situación bastante normal en la actualidad). 
concreta del peso) que con el subprincipio de necesidad elaborado por Alexy, cuya fórmula ya fue expuesta en líneas anteriores.

En particular, en el ámbito del Derecho del Trabajo, y en relación a la comprensión del subprincipio en cuestión, Gamonal señala que "deberán preferirse medidas no invasoras de los derechos fundamentales del trabajador" ${ }^{31}$; Ugarte, por su parte, comprende por tal subprincipio implica "que la medida o restricción del derecho fundamental sea indispensable para lograr el fin legítimo, no existiendo una alternativa menos aflictiva o costosa"32 y, finalmente, Caamaño indica que "la medida debe ser necesaria, en el sentido de que no exista otra medida más moderada para la consecución de tal propósito con igual eficacia”33. El profesor Ugarte al utilizar la expresión "indispensable” parece acercarse a una comprensión cerrada de este subprincipio, y adopta una comprensión más estricta que el propio Alexy. Lo mismo Gamonal, restringiendo las preferencias de medidas a aquellas que no vulneren los derechos fundamentales del trabajador, lo que en principio es coherente con lo propuesto con Alexy, sin embargo, puede inducir a error al intentar obviar la posibilidad de conflicto entre derechos fundamentales (presupuesto de la aplicación del principio de proporcionalidad $)^{34}$.

El resultado de la aplicación del subprincipio de necesidad está condicionado por el ejercicio imaginativo fáctico que realice el juez en relación con los principios en colisión ${ }^{35}$ (principios que también fueron puestos en juego por la interpretación del juez, respecto de la medida adoptada). En primer lugar, queda sujeta la solución a la apreciación (valoración subjetiva) sobre lo intrusiva que sea la medida, adoptada por el empleador en nuestro caso, en comparación con otra que podría satisfacer de igual forma el principio beneficiado (la mayoría de los casos, como ya se señaló, el derecho de propiedad). Pero no solo eso, sino que también está sujeto al desarrollo alternativo de medidas que proponga plantearse imaginariamente el juez. Termina siendo ante todo, un juicio de valoración subjetiva del juez, que en la argumentación jurídica se plasmará mediante explicitación simple de una medida

31 Reconoce cuatro dimensiones diversas del subprincipio de necesidad: necesidad material (el medio usado debe ser el que afecte en menor medida los derechos fundamentales), exigibilidad espacial (el medio usado debe ser aquel que estatuya el menor ámbito de limitación del derecho), exigibilidad temporal (la medida debe regir el menor tiempo posible) y exigibilidad personal (la medida debe afectar al menor número de personas posibles). GAMONAL CONTRERAS, Sergio, "Procedimiento de... (n. 26), pp. 33-34. Sin duda que se supera una comprensión básica del subprincipio de necesidad, sin embargo, desde la teoría de Alexy, parte de estos elementos están ubicados en la fórmula del peso, y en particular, en la seguridad de las apreciaciones empíricas. La inclusión de estos elementos, a mi parecer, es sumamente útil, pero para un ejercicio hermenéutico que recaerá sobre los principios y la medida en cuestión; mas como parte del juicio de ponderación pierden su relevancia, e incluso, permiten que se caída en contradicciones internas en la aplicación del método.

32 Ugarte Cataldo, José Luis. Los Derechos Fundamentales del Trabajador: el nuevo procedimiento de tutela laboral. Santiago, Chile: Colección Ensayos Jurídicos, Universidad Alberto Hurtado, No 2, 2006, p. 22.

33 CAAmaño Rojo, Eduardo. "La eficacia de los Derechos Fundamentales en las relaciones laborales y su reconocimiento por la Dirección del Trabajo”, en: Revista de Derecho (Valparaíso), vol. 1, No XXVII, p. 24. Valparaíso, Chile: Pontificia Universidad Católica de Valparaíso, 2006.

34 Para la deducción de la regla de la necesidad propone la siguiente situación: "Supongamos que hay una alternativa $N$ a $N$, que es suficientemente adecuada para promover P1, y que infringe menos P2 que $N$. En esta situación, P2, y P2 prohíben conjuntamente $N . N$ no es necesaria para realizar P2, porque P1 puede ser cumplido con un costo menor". AleXY, Robert. "Derechos, razonamiento... (n. 5), p. 46. En otro lugar señala explícitamente que: "este subprincipio exige que de dos medios igualmente idóneos sea escogido el más benigno con el derecho fundamental afectado”. AlEXY, Robert, "Epílogo... (n. 7), p. 28.

35 Similar afirmación se encuentra en GarCía DALmado, Juan Antonio, “El juicio de... (n. 27), p. 271. 
alternativa, que perfectamente, a otro sujeto puede parecerle más intrusiva que la primera. No para todos la medida será igual de intrusiva; dependerá desde dónde se haga tal evaluación. El principio de proporcionalidad será ideal para que el juez pueda esconder sus reales intenciones, limitando la posibilidad de crítica racional sobre su argumentación jurídica, mediante la propuesta de una medida alternativa ad hoc. La evaluación sobre la necesidad de la medida queda sujeta a las apreciaciones subjetivas del juez, y sus posibilidades creativas de generar escenarios diversos de menor intrusión.

La necesidad de la medida nuevamente se encuentra sujeta a una previa interpretación de la medida y sus alcances, y los derechos fundamentales que colisionan. En el procedimiento de Tutela Laboral su valoración sobre los alcances y fines del derecho de propiedad, lo que supone una postura frente a la comprensión de este último y, además, una concepción del sistema de derechos, la posibilidad de que existan límites internos o externos, mas no se puede afirmar que desde el vacío irá a evaluar la "necesariedad" de la medida, como si ni siquiera hubiese sido necesaria una aproximación previa a lo jurídico.

Lo que sostengo es que nuevamente el análisis sobre la necesidad de la medida implica una interpretación del derecho de propiedad que ejerce el empleador, sus alcances y límites internos. No se trata simplemente de un análisis empírico reducido a las apreciaciones fácticas objetivas que realice el juez como observador externo, sino más bien, una comprensión jurídico normativa de los derechos en conflicto y de la medida adoptada. Si al juez, visceralmente no le parece "necesaria" la medida adoptada por el empleador, tendrá que emprender un ejercicio imaginativo para proponer medidas alternativas, que a su juicio, sean menos lesivas (asumiendo que la lesividad pueda ser gradual). Básicamente, la necesariedad podrá ser resuelta en la creación imaginaria de esa medida, y en las herramientas retóricas que tenga el juez para convencer al público de que la medida que él propone es menos lesiva que la reclamada. Ahí, sin duda, le será necesario recurrir a la definición conceptual de los principios (derechos fundamentales) en conflicto.

\subsubsection{Principio de proporcionalidad en sentido estricto y ley de la colisión}

Suponiendo que se han aprobado los exámenes de idoneidad y necesidad, ya criticados, y solo en tal caso, será procedente someter la medida al juicio de proporcionalidad en sentido estricto. El profesor José Luis Ugarte comprende directamente lo planteado por Alexy, y así señala que: "cuanto mayor sea el grado de no cumplimiento o de no satisfacción de un derecho fundamental, tanto mayor debe ser la importancia de cumplimiento de otro" ${ }^{36}$. El profesor Gamonal, al referirse a este subprincipio, indica que "el límite de los derechos fundamentales debe ser racional tanto respecto del objeto de la medida como de sus efectos" 37 , agregando que "la racionalidad respecto del objeto se vincula con el fin perseguido con el contrato de trabajo [...] que en definitiva no puede alterar derechos fundamentales por el solo objetivo económico del contrato o de la actividad empresarial"38.

36 Ugarte Cataldo, José Luis, "Los Derechos Fundamentales (n. 32), p. 24.

37 Gamonal Contreras, Sergio, "Procedimiento de... (n. 26), p. 34.

38 Ibid. 
Tal vez aquí es donde más densa se podría poner la discusión, y sin embargo, a pesar de ser un punto determinante en la metodología de Alexy, es el subprincipio menos desarrollado en la doctrina nacional. El juicio de ponderación aparece como complejo, con la existencia de tres subprincipios constituyentes del principio de proporcionalidad (idoneidad, necesidad y proporcionalidad en sentido estricto); sin embargo, recién en la última etapa comenzaría la ponderación misma, y la verdadera complejidad de análisis. Si se quiere acoger o rechazar la aplicación del principio de proporcionalidad como método de resolución de la colisión de derechos fundamentales, sin duda hay que pronunciarse sobre la estructura de la ponderación. Por eso, iremos paso por paso abordando el desenvolvimiento de este subprincipio, y la estructura de la ponderación. Para desarrollar esta tarea nos valdremos del trabajo realizado por Carlos Bernal, que es lo suficientemente esquemático y preciso.

Si el plan es aplicar el principio de proporcionalidad propuesto por Alexy, entonces habrá que hacerse cargo de lo que él entiende por principio de proporcionalidad en sentido estricto. Al respecto señala que: "este subprincipio dice lo que significa la optimización relativa a las posibilidades jurídicas [recordar que los otros elementos implicaban un análisis sobre las posibilidades fácticas]. Es idéntico a una regla que podemos denominar "ley de ponderación" 39 . No es baladí lo que aquí se señala, pues el último paso de ponderación suele reducirse a la enunciación básica mencionada previamente, sin embargo la idea de Alexy es mucho más compleja y, como también se señaló anteriormente, la estructura de la ponderación estaría constituida por la ley de la colisión (o ponderación), la fórmula del peso y las cargas de argumentación ${ }^{40}$. Lo que suele comprenderse como proporcionalidad en sentido estricto no es sino solo una de las aristas de la ponderación en su última fase.

La fórmula básica de la ley de la colisión es la ya tantas veces reiterada: "Cuanto mayor es el grado de la no satisfacción o de afectación de uno de los principios, tanto mayor debe ser la importancia de la satisfacción del otro". De aquí se deduciría que la primera variable a analizar sería la intensidad de la afectación de un principio sobre el otro, para lo cual se proponen como estándares de medición los siguientes: leve, medio o intenso. Sin embargo, aún no basta con la determinación de la intensidad de la afectación para justificar jurídicamente la proporcionalidad de la medida, sino que es necesario aún añadir dos elementos más. El primero de ellos es el "peso abstracto" de cada uno de los principios ${ }^{41}$, el segundo (tercero, en el conteo total) es la consideración de la variable sobre la "seguridad de las apreciaciones empíricas que versan sobre la afectación que la medida en el caso concreto [...] proyecta sobre los principios relevantes" ${ }^{2}$. En esto consistiría la ley de la colisión.

Esto no nos aclara mucho, porque aún no sometemos todas las variables concurrentes y relevantes a la fórmula del peso ${ }^{43}$, que permite resolver aritméticamente, mediante el

\footnotetext{
39 ALEXY, Robert, "Derechos fundamentales... (n. 10), pp. 8-9.

40 Bernal Pulido, Carlos, op. cit. p. 21

41 "La variable del peso abstracto se funda en el reconocimiento de que, a pesar de que a veces los principios que entran en colisión tengan la misma jerarquía en razón de la fuente del derecho en que aparecen -por ejemplo, dos derechos fundamentales que están en la Constitución tienen la misma jerarquía normativa- en ocasiones uno de ellos puede tener una mayor importancia en abstracto, de acuerdo con la concepción de los valores predominante en la sociedad” Ibíd.. p. 23.

42 Ibid.

43 Ibid. pp. 24 y ss.
} 
cálculo de intensidades de interferencia y satisfacción de los principios en colisión, la primacía condicionada de uno de los principios por sobre el otro. Todo tras una traducción matemática del conflicto. Solo entonces sabremos cuál es el derecho que en el caso concreto precede al otro. Sin embargo, aún aquí puede suceder que matemáticamente ambos principios pesen lo mismo. Quienes sostienen que la colisión de derechos fundamentales es posible, y que el juicio de ponderación es un método racional de solución, deberían, al menos, conceder que hay posibilidades de empate, y que la solución de tales casos no es del todo clara. Para aquello Alexy propone un tercer elemento en la estructura de la ponderación: las cargas de argumentación.

La comparación beneficio-perjuicios de los principios en colisión, evaluada mediante la escala de intensidad propuesta por Alexy no es del todo pacífica. Las medidas "leve", "media" o "grave", abren un gran espacio para la determinación subjetiva del juez. Nuevamente el juez tendrá previamente que determinar al menos la esencia de cada uno de los derechos que entran en colisión, pues entiendo, solo así podríamos evaluar una medida como gravemente intrusiva (habría que saber qué se está vulnerando ilegítimamente). Esto implica, nuevamente, que el juez previamente debe interpretar los principios que entran en juego. Supone una valoración respecto de la importancia y alcance de los derechos que entran en conflicto; valoración que podrá excluir de la argumentación jurídica señalando simplemente la intensidad de la afectación, acogiéndose a la metodología propuesta por Alexy. Sin embargo, no existe ningún criterio objetivo que permita omitir dicha argumentación jurídica, y darla por obvia, menos aún la división tripartita propuesta por Alexy en la escala de intensidad. E incluso si así se creyera, ¿no estaríamos frente a un caso de subsunción de la medida a alguno de los parámetros de intensidad? Subsunción en que la premisa mayor estará constituida por los grados de afectación de principio correspondiente, mientras que la premisa menor corresponderá a la interpretación de la medida en cuestión. Sin embargo, aquello también supone una interpretación de las categorías de intensidad. Tal como señala Bernal, a propósito de los límites racionales de la ponderación "no está claro cuál es el punto de vista a partir del cual debe hacerse la graduación. Y esta duda solo puede ser resuelta por el operador jurídico -el juez sobre todo, después de adoptar una posición material o ideológica" ${ }^{44}$. Podría objetarse que estas situaciones se presentan en los casos difíciles, y no en los fáciles, sin embargo, en materia de derechos fundamentales parece demasiado arriesgado sostener que existen "casos fáciles", más aún si en materia de principios se desecha la utilidad funcional de la subsunción (podría sostenerse esta apreciación del Derecho en general, pero este no es el espacio para aquella discusión). Para el juez se tratará de un caso fácil, obviamente, si supone que todos quienes tengan acceso a la sentencia comparten sus creencias y posición ideológicas.

El Derecho del Trabajo tiene como uno de sus elementos caracterizadores el principio pro operario, y su desarrollo se ha concebido con una finalidad clara: la protección del trabajador frente al empleador, en diferentes dimensiones. En tal sentido, es evidente que los problemas intersubjetivos en esta esfera del Derecho no se resolverán de la misma forma que en cualquier otra rama (civil o comercial). Básicamente, porque aquí el presupuesto de

44 Bernal Pulido, Carlos, op. cit. (n. 14), p. 29. 
igualdad de las partes está trastrocado por la relación de subordinación y dependencia que constituye toda relación laboral. En este sentido, no será una cuestión irrelevante cuáles son ámbitos de discreción que se le dejen al juez al momento de fallar, y en especial, cuál es el papel del principio pro operario en el balanceo de derechos fundamentales. En la graduación de intensidad se pueden manifestar los prejuicios que se tengan frente al derecho de propiedad y la posición del empleador, beneficiando o perjudicando al trabajador. La discusión, de ser racional y basarse en la argumentación jurídica hecha por el juez, pasará a establecerse en los siguientes términos: ¡es un juez pro empleador o pro trabajador? Es en ese ámbito donde pasará a decidirse el resultado del litigio, escondido tras toda una maraña de fórmulas ad hoc, que servirán de mascarada para las valoraciones subjetivas del juez. Nuevamente la resolución del caso pasará por los alcances que el juez determine para el derecho de propiedad y el derecho fundamental que el trabajador considere lesionado; interpretación que no necesariamente deberá señalar en la sentencia, aunque de todas formas irá implícita.

Si la intensidad de afectación deja abierta la entrada a la valoración subjetiva y la ideología del juez, más aún lo hace la consideración de los pesos abstractos de los derechos en conflicto ${ }^{45}$ (siempre y cuando los derechos que colisionan no sean los mismos). Implica recoger, ya no como método de solución definitiva, pero sí como parte de la estructura de la ponderación, la idea de jerarquía entre derechos fundamentales (en tres niveles) ${ }^{46}$. Es aquí en donde el juez laboral deberá cumplir una difícil tarea, pues está balanceando derechos fundamentales entre pares, por lo mismo, no sería razonable, que sistemáticamente el fin protector del Derecho del Trabajo hiciera inclinar la balanza hacia un lado, previo a resolver el caso concreto. No se trata de colisión entre cualquier categoría de derechos, sino que de derechos fundamentales, y por lo mismo, su razonamiento debe ir más allá de la particularidad protectora del Derecho del Trabajo. La relación de poder empleador-empleado, no puede por sí misma servir como fundamento de la decisión judicial, a lo sumo, puede ser considerada solo con la finalidad de fundamentar la aplicación del juicio de ponderación, mas no en la elección de la decisión misma. Hay que recordar que si lo que se pretende es constitucionalizar el Derecho del Trabajo, de lo que hablamos es de la eficacia horizontal de los derechos fundamentales, y no cabe asimilarlo a la protección de un particular frente al poder del Estado, pues incluso esta misma teoría ha abandonado la idea liberal de que es esa, y no otra, la función de los derechos fundamentales. Es complejo sostener que asimilamos la relación Estado-individuo, a la relación empleador-trabajador, a la hora de aplicar el Derecho, si precisamente para fundamentar lo segundo recurrimos a la teoría de la eficacia horizontal de los derechos fundamentales. Es extraño, porque se pretende aplicar la teoría de la eficacia horizontal de los derechos fundamentales, pero a la vez arrastrar un resabio liberal antiguo, como es la idea de relación de poder Estado-individuo a empleador-empleado, para darle

\footnotetext{
45 Al respecto señala Bernal: "El peso abstracto es una variable muy singular, que remite siempre a consideraciones ideológicas y hace necesaria una toma de postura por parte del intérprete sobre aspectos materiales, relativos a la idea de Constitución, Estado y de justicia”. Bernal Pulido, Carlos, op. cit. (n. 14), p. 30.

46 "Dado que los pesos abstractos de los principios son independientes de cualquier circunstancia concreta, deberíamos tener a nuestra disposición una asignación de peso abstracto para cada principio que establece un derecho constitucional, deberíamos tener una escala de ordenación abstracta de los derechos". MORESo, Juan José. "Alexy y la aritmética de la ponderación". En: VV.AA. Derechos sociales y ponderación. Madrid, España: Fundación Coloquio Europeo, 2007, p. 3.
} 
una caracterización especial a esta relación ente "horizontales" (a medias). Si se pretende hacer tal relación es conveniente que al menos sea el legislador, ente legitimado democráticamente, quien establezca una presunción o desbalanceo de los derechos fundamentales a favor del trabajador de manera explícita ${ }^{47}$, mas no dejarlo sujeto a la arbitrariedad judicial, oculta tras fórmulas poco claras. Eso sería realmente tomar un poco los derechos en serio.

Respecto del último punto, la "carga de la argumentación”, Alexy habría asumido dos posturas contrarias, en diferentes textos. En uno habría sostenido, en virtud del principio democrático, una presunción a favor del legislador (in dubio pro legislatore), y en otro, a favor de los particulares (in dubio pro libertate) ${ }^{48}$. Dicha diferencia de criterios no es menor, pues lleva a solucionar los casos de empate (que la mayoría de las veces el juez podrá obviar mediante la inclusión dirigida de todas las herramientas retóricas que se le otorgan). Suponiendo que en el procedimiento de Tutela se llegase a un caso de empate, ¿cuál será la solución aplicable? Trasladando los criterios de Alexy al Derecho Laboral podemos señalar que tenemos dos opciones: en la duda a favor del empleador: o bien, en duda a favor del trabajador (in dubio pro operario). Este segundo principio es reconocido por la doctrina nacional en la aplicación del derecho sustantivo, por lo que parece razonable sostener que en casos de empate la balanza ha de cargarse hacia el lado del trabajador. En ese sentido, podría sostenerse que la solución (en todos casos doctrinaria) sería fallar a favor del trabajador. Pero, y conforme con lo señalado anteriormente, inclusive aquí es necesario que se establezca de manera explícita dicha presunción, pues si bien es aplicable a la solución de litigios en que lo disputado tiene un carácter eminentemente patrimonial, la naturaleza del Procedimiento de Tutela Laboral no tiene por qué ser servil a esa lógica. Estamos en un caso en que entran en colisión derechos no patrimoniales, y más aún, se trata de derechos fundamentales, por lo que su resolución ha de tener una lógica propia, si bien enmarcada dentro del ámbito del

47 Obviando, por ahora, las objeciones que tal presupuesto pudiese tener constitucionalmente.

48 Según Gloria Lopera, en respuesta al desamparo que sufrirían los derechos fundamentales comprendidos como principios señala que es pertinente "afirmar la prevalencia prima facie de los derechos individuales sobre los colectivos, expresada en una carga de argumentación a favor de los primeros [in dubio pro libertate][...] No obstante al tiempo que afirma lo anterior sostiene, por otro lado, la prevalencia de las reglas sobre los principios, argumentando que aquellas tienen un carácter prima facie diferente y esencialmente fuerte respecto al que poseen los principios. La razón de esta mayor fuerza de las reglas radica en que estas, además de venir respaldadas por principios sustanciales, cuentan con el apoyo de principios formales que ordenan seguir las determinaciones impuestas por una autoridad legítima. En sus trabajos más recientes, este planteamiento ha desembocado en el reconocimiento de un margen estructural para la ponderación a favor del legislador, bajo el entendido de que "si las razones para la intervención son tan fuertes como las razones que juegan en su contra, la intervención no es desproporcionada”, lo que se traduce en una suerte de "in dubio pro legislatore". LOPERA MESA, Gloria Patricia. "Los derechos fundamentales como mandatos de optimización”, en: Doxa. Cuadernos de Filosofía del Derecho No 27, p. 242. Alicante, España: Universidad de Alicante, 2004. Efectivamente, Alexy señala que "En este caso [se refiere a la jurisprudencia que analiza en su texto] de lo que se trata es de que, si se presenta un empate $1 / 1$, al legislador le está permitido no actuar. Dado que cuando se presenta esta constelación también le está permitido actuar si lo desea, entonces se debe aceptar que existe un margen de acción, entendido de acuerdo con la definición anteriormente expuesta, como un espacio de discrecionalidad en el que está permitido actuar o no actuar [...] se trata de un margen acción estructural [ si las razones para la intervención son tan fuertes como las acciones que juegan en su contra, la intervención no es desproporcionada" ALEXY, Robert, "Epílogo... (n. 7), p. 45. Mientras que en otro lugar: "No es posible un orden de los principios, o un orden de valores que, de una manera intersubjetivamente controlable, conduzca en cada caso a un único resultado; un orden tal podría ser llamado "orden duro". Pero, lo que es posible es un orden blando con prioridades prima facie. El núcleo correcto de la teoría material de los derechos fundamentales propuesta por Böckenforde es que, como se expusiera más arriba, puede presentarse una prioridad prima facie de los principios de libertad jurídica y de la igualdad jurídica, es decir, una carga argumentativa a favor de estos principios”. AleXY, Robert. “Teoría... (n. 1), p. 549. 
trabajo, ha de mirar más a la calidad de persona humana de sus titulares que a su condición particular de empleador y trabajador. Por lo mismo, es necesario reiterar que la solución de estos casos, si se pretende seguir defendiendo la aplicación del principio de proporcionalidad, ha de ser tipificada por el legislador, y no debe quedar sujeta a la arbitrariedad del juez.

\section{BUENAS INTENCIONES, MAL CAMINO}

Las críticas realizadas a la irracionalidad de la solución propuesta por Alexy en casos de colisión de derechos fundamentales llegan desde variadas direcciones. Este, sin embargo, no es el lugar para ahondar en todas ellas. Solo se ha mencionado aquellas que muestran lo irracional del método de ponderación internamente, aunque también podría criticarse, por ejemplo; la comprensión de los principios como mandatos de optimización ${ }^{49}$; afirmar que no todos los principios son mandatos de optimización ${ }^{50}$; que no todos los derechos fundamentales son susceptibles de ponderación (no se puede ser "un poquito esclavizado", "levemente torturado", o en nuestro caso, no se puede vulnerar gradualmente la "garantía de indemnidad", no se puede sostener una "leve" represalia sobre el trabajador), pues no es aceptado que todos los derechos fundamentales puedan ser limitados. Ideas tan contradictorias como que la aplicación del juicio de ponderación implica una sobreconstitucionalización del Derecho, que garantizaría demasiado (Böckenförde) o demasiado poco (Habermas) ${ }^{51}$; comprender los derechos fundamentales como principios, y los principios como valores, suponen un orden objetivo de estos últimos, la existencia de una "constitución material", incognoscible plenamente por el sujeto aplicador del Derecho, y una comprensión más axiológica de los derechos fundamentales, que deóntica, como efectivamente debiese ser (del análisis sobre "deber ser" en el caso concreto, se pasa a un análisis sobre "lo bueno", abriéndose amplio camino a la arbitrariedad judicial). Incluso el fundamento mismo de la aplicación del principio de proporcionalidad, esto es la separación fuerte entre principios y reglas, es bastante discutible ${ }^{52}$; la idea de que incluso el juicio de ponderación

\footnotetext{
49 En ese sentido, de entrada, "no queda claro si el principio es él mismo un mandato de optimización (de la validez o aplicabilidad de una norma) o más bien el objeto de un mandato de optimización". LOPERA MESA, Gloria Patricia, "Los derechos... (n. 48), p. 218. La relevancia de esta suspicacia radica en que si se trata de un mandato de optimización, es porque mandata optimizar algo. Ahora, si el principio es ese mandato mismo, ¿cuál es el objeto a optimizar? Y además, la "definición de los principios como mandato de optimización envuelve una paradoja ya que, como ha señalado Aarnio, un mandato de optimización es en cualquier caso una regla: o se sigue o no se sigue. De este modo, el mandato de optimización e también una regla que no puede ser aplicada "más o menos". Se optimiza o no se optimiza"”. Ibid., p. 219.

50 Tal distinción habría sido propuesta por Manuel Atienza y Juan Ruiz Manero: "Principios en sentido estricto y directrices se asemejan en que ambos formulan de modo abierto en condición de aplicación, pero mientras los principios en sentido estricto presentan de manera cerrada el modelo de conducta prescrito (consecuente), las directrices lo configuran de manera abierta [...] los primeros, una vez comprobado que desplazan a otros principios en un balance de razones, exijan un cumplimiento pleno, mientras en las directrices prescriben el cumplimiento de un estado de cosas en la mayor medida posible". Ibid., p. 221. Por ejemplo no cabría la posibilidad de afirmar que se actúa "con un poco de buena fe", en cambio sí se puede afirmar que el derecho a vivir en un medio ambiente limpio y sano está siendo cumplido en la mayor medida posible.

51 AleXY, Robert, "Epílogo... (n. 7), pp. 14 y ss.

52 En este sentido se señala que "no esta claro si la tesis fuerte de la separación que se sostiene en un plano ontológico (reglas/ principios) resiste su traslación al plano funcional (subsunción/ponderación) [...]”. GARCía FigueroA, Alfonso. "Ontología y función de los mandatos de optimización”. En: VVAA. Derechos sociales y ponderación. Madrid, España: Fundación Coloquio Europeo, 2007, p. 6. La idea de la constitucionalización del derecho implica que la Norma Fundamental irradiará todas las
} 
implica una jerarquización en el caso concreto, y no se diferenciaría en gran medida de una comprensión jerárquica estática de los derechos fundamentales; o la consecuencia nefasta de crear "derechos "príncipe" y derechos "cenicienta" 53 . Se trata de un método que se mira como simple y objetivo, pero en realidad, ni siquiera sus seguidores, se han puesto de acuerdo en cómo comprender la estructura del Principio de proporcionalidad. Algunos señalan que está compuesto por subreglas, otros por subprincipios, e incluso se ha llegado a afirmar que se trata de juicios (de adecuación, necesidad y proporcionalidad en sentido estricto). Puede haber un problema de traducción de los textos originales de Alexy, no obstante, es exigible al menos que quienes siguen su propuesta se decidan por una otra nomenclatura, pues no es lo mismo hablar de subreglas que de subprincipios, menos aún para Alexy.

La aplicación del principio de proporcionalidad en los casos de colisión de derechos fundamentales, y en especial, en el procedimiento de Tutela Laboral no responde a las necesidades de certeza jurídica requeridas por nuestro ordenamiento jurídico. Como ya quedó claro hasta aquí, la posibilidad de revisar y criticar racionalmente la sentencia jurídica dictada por el juez queda bastante reducida. A lo sumo, podrá siempre señalarse que la apreciación adoptada por el juez carece de fundamento y racionalidad. Las críticas que hemos expuesto podrán predicarse de cualquier sentencia que se dicte siguiendo al pie de la letra el método de solución propuesto por Alexy. Esa básicamente será la falla estructural de la jurisprudencia si sigue este camino. Por lo mismo, no es lo suficientemente precisa y racional esta forma de argumentación, y con ello, pierde fuerza la legitimidad del fin protector que implica incluir este procedimiento especial. Todo lo bueno que se pretende lograr con la aplicación horizontal de derechos fundamentales, cae ante la irracionalidad de la solución, o al menos, las ventanas abiertas a la arbitrariedad del juez tras la enmarañada construcción teórica de proporcionalidad. Se debe pensar que la argumentación jurídica debe cumplir con la tarea de convencer, si no a todo, al menos a la gran mayoría del público, por lo que en cualquier caso no se deben dar por supuestas y compartidas las apreciaciones ideológicas del juez. Lo ideal es que la argumentación jurídica sea completa y clara, y que no se esconda tras artimañas técnico-teóricas las verdaderas razones del fallo en una u otra dirección. Esta tarea se ve intensificada en el caso del juez laboral, pues la sentencia que dictará irá directamente dirigida al trabajador, que tendrá que comprenderla en la mayor medida posible.

Por otro lado, aunque las intenciones del juez parezcan completamente loables, aquello no justifica abrir las puertas a la arbitrariedad judicial, y menos puede llevar a que este se desentienda de su posición en la resolución de conflictos intersubjetivos. Toda persona

normas del ordenamiento jurídico, lo que incluye a las reglas. Por lo mismo, no es posible, ni deseable encontrar reglas puras, debido al efecto de irradiación e impregnación de la Constitución. La característica propia de este tipo de normas de que no son susceptibles de ser aplicadas gradualmente, sino solo estarían sujetas a un todo o nada, elemento que se perdería de manera paradójica, más aún si las excepciones a la regla dejan de ser susceptibles de determinación previa y taxativa. El autor llama a esta paradoja el efecto "Caballo de Troya".

53 "[T] $[$ anto la jerarquización como el balancing test tienen relación con la doctrina de las libertades preferidas, y no solo el derecho norteamericano, pues ambos métodos -más acentuadamente el primero, más discretamente el segundo- colocan a algunos derechos -entre los cuales suele estar el derecho a la información- en posiciones de preferencia, y convierten a otros en "cenicientas jurídicas", cuya medianoche es cruzarse con un derecho más fuerte [...]". SERnA, Pedro y Toller, Fernando. La interpretación constitucional de los derechos fundamentales. Una alternativa a los conflictos de derecho. Buenos Aires, Argentina: Editorial La Ley, 2000, p. 17. 
tiene derecho a un juicio justo, y en tal sentido, se debe asegurar la imparcialidad, impartialidad y racionalidad del juez que vaya a dictar sentencia. No es conveniente que en pro del activismo judicial, se le otorguen herramientas serviles a la arbitrariedad del juez, y sus preferencias ideológicas personales, desatendiendo los derechos fundamentales, sujetando la suerte de las partes la azarosa situación de que el juez sea más o menos liberal, o más o menos socialista. E incluso, sosteniendo que lo que se busca en el juicio no es la verdad misma (objetiva), sino que se resuelva un conflicto con fuerza de imperio, el deseo no ha de ser abandonar por completo la necesaria justificación de la sentencia, sino todo lo contrario.

El ejercicio retórico de convicción que realiza el juez en la sentencia debe ser lo más completo posible, y en ese sentido, la aplicación del principio de proporcionalidad es una herramienta negativa, pues permite llenar de conceptos vacíos y empobrecer la argumentación jurídica tras tecnicismos que aparecen como evolucionados y progresistas, limitando no solo las posibilidades de crítica al razonamiento del juez, sino también las posibilidad de comprensión de su sentencia. Se suma a esto, la circunstancia de que el juicio de proporcionalidad resuelve de manera exclusivamente particular el conflicto en cuestión, y abandona la pretensión de que el juez al fallar tenga en cuenta la posibilidad de universalizar su juicio concreto. Por lo tanto, la posibilidad de lograr certeza jurídica y predictibilidad de las sentencias se reduce al mínimo. Basta con que un ínfimo elemento fáctico varíe de un caso a otro (la duración o alcance de la medida, o en espacio físico en que se verifique), para que la solución pueda resultar totalmente opuesta. Y eso en sí mismo no es lo más grave, sino que además existe la posibilidad de que aquel problema se solucione sin necesidad de explicitar directamente cuál es la interpretación de las normas o principios en juego en el caso concreto (a pesar que, de hecho, la realiza, pues desde ahí resuelve el caso).

Otro elemento relevante en la comprensión del juicio de proporcionalidad, es la supuesta "novedad" de estas tendencias neoconstitucionalistas, y la consideración de la Constitución como una fuente de Derecho vinculante directamente aplicable, "idea de fuerza vinculante de la constitución [que] se entiende como opuesta a una noción de constitución de manifiesto político, cuya concreción e inclusión en el ordenamiento jurídico queda entregada a las demás fuentes del Derecho" 54 . Luego, la afirmación que sostiene que "los preceptos sobre derechos fundamentales constituyen principios, y estos, a su vez, son la expresión, en términos de deber ser, de los valores, ubicados en el plano del ser" ${ }^{55}$. En este contexto, definir qué es un valor no es una tarea sencilla. Puede referirse a moral o apreciaciones ideológicas, sin embargo, en ambos casos la racionalidad de la decisión dejaría bastante que desear. Por ello, no es pacífica tampoco la comprensión de los derechos fundamentales como manifestación de valores subyacentes a la constitución formal.

Entender los derechos fundamentales como principios disminuye la racionalidad de las sentencias y, por lo mismo, la posibilidad predictiva ideal del Derecho. En otras palabras, la comprensión de las normas como una totalidad compuesta por principios y reglas, tiende a borrar la certeza jurídica como elemento relevante del juicio, y con ello, la posibilidad de evaluar alternativas de acción por parte de los agentes racionales que concurren a los tribu-

\footnotetext{
54 Aldunate Lizana, Eduardo, op. cit. (n. 18), p. 88.

55 Aldunate LizANA, Eduardo, op. cit. (n. 18), p. 90.
} 
nales para someter sus conflictos a la decisión del juez. Este erróneo camino puede evitarse si lo que se hace en realidad es simplemente interpretar las normas que concurren, y explicitar las razones y elementos que constituyen determinada interpretación, idealmente, acogiéndose a las normas legales vigentes, pues es el legislador quien tiene la legitimación democrática para desarrollar tal tarea. No es jurídicamente correcto dejar las decisiones sobre derechos fundamentales a las apreciaciones de valor subjetiva de los jueces en una sociedad pluralista y democrática, sino que se debe ser más exigente con la argumentación jurídica. De lo contrario, dejaremos a criterio del juez cuándo una medida afectó o no un derecho fundamental, dependiendo de los fines que él persiga, casi como agente político. Él no es el sujeto legitimado democráticamente para establecer los alcances de la Constitución, sino que esta tarea le corresponde al Legislador, y en ese sentido siempre será conveniente fundamentar antes las decisiones en la Ley, que directamente en la Constitución.

Finalmente, recogemos la crítica propuesta por el profesor Aldunate, y que creo que se hace cargo del núcleo del problema: "La distinción entre reglas y principios solo es posible para una teoría que no distingue entre textos normativos y norma como entidad de significado resultante de un proceso de construcción normativa" ${ }^{56}$. Se caricaturiza a la subsunción como una aplicación mecánica del derecho, pero en realidad, lo que plantea Alexy no es muy diferente a la subsunción. De hecho, en cada uno de los pasos desarrollados en el principio de proporcionalidad, si es que pudiesen aplicarse de manera correcta y racional, habría que ir subsumiendo hechos, conceptos, o medidas, a la comprensión de determinadas categorías. Sin embargo, subsumir no significa solo la evaluación comparativa mecánica de una premisa menor y una mayor, sino que implica un ejercicio hermenéutico complejo, en la determinación de los derechos que concurren y los hechos que se presentan como hipótesis de aplicación. Lo ideal es que el juez laboral en su sentencia, en vez de enredarse con la colisión de derechos fundamentales, desarrolle su línea argumentativa mediante la interpretación de los derechos, estableciendo si efectivamente concurre en el caso concreto un derecho, o simplemente, su limitación interna lo deja desvalido, y sin cobertura sobre los hechos alegados. Una correcta interpretación de los derechos fundamentales permitirá olvidar la colisión de derechos, y la negativa comprensión de aquellos como un "mercado de derechos", en constante competencia, donde no solo los derechos concebidos abstractamente son los que pierden, sino que sus propios titulares se ven sistemáticamente desplazados.

Comprender la subsunción en su versión caricaturizada, implica concebir que el lenguaje natural es transparente, y la mente del juzgador serviría solo como una máquina procesadora, vacía de contenido, pero no, nadie está sosteniendo aquello; el juez, como cualquier otra persona, realiza ejercicios complejos de comprensión de cualquier fenómeno que se le presenta como exterior, tiene prejuicios y valoraciones personales, pero en nuestro caso concreto es lo mejor para todos que plantee y desarrolle ampliamente sus apreciaciones, antes que esconder sus intenciones tras elucubraciones teóricas inconsistentes. En todo caso, incluso la ponderación implica una decisión sobre lo justo en el caso concreto, y en tal sentido, el resultado de su aplicación será la creación de una norma aplicable al caso.

56 Aldunate LiZANA, Eduardo, op. cit. (n. 18), p. 91. 


\section{BIBLIOGRAFÍA}

AldunATE LiZANA, Eduardo. "Aproximación conceptual y crítica al neoconstitucionalismo”; en: Revista de Derecho, vol. XXIII No 1. Valdivia, Chile: Universidad Austral de Chile, Facultad de Ciencias Jurídicas y Sociales, 2010.

ALEXY, Robert. "Derechos fundamentales, ponderación y racionalidad”, en: Revista Iberoamericana de Derecho Procesal Constitucional, enero-junio de 2009. Disponible en: <http://www.iidpc.org/revistas/11/ pdf/19_29.pdf> [Consultado 10 de noviembre de 2011].

ALEXY, Robert. "Sobre los derechos constitucionales a protección”. En: VV.AA. Derechos sociales y ponderación. Madrid, España: Fundación Coloquio Jurídico Europeo, 2009.

AleXY, Robert. “Epílogo a la Teoría de los Derechos Fundamentales” (trad. del alemán de Carlos Bernal Pulido) en: Revista española de Derecho Constitucional, Año 22, No 66, septiembre-diciembre 2002.

AlEXY, Robert. "Derechos, razonamiento jurídico y discurso racional", en: Isonomia: Revista de Teoría y Filosofía del Derecho No 21, octubre 1994. Alicante, España: Universidad de Alicante.

AleXY, Robert. Teoría de los derechos fundamentales. Madrid, España: Centro de Estudios Constitucionales, 1993.

Bernal Pulido, Carlos. "La ponderación como procedimiento para interpretar los derechos fundamentales". En: Cáceres, E.; Flores, I. B.; Saldaña J; y Villanueva, E. (coord.). Problemas contemporáneos de la filosofía del derecho. México: Universidad Nacional Autónoma de México, 2005. Disponible en: <http:// www.bibliojuridica.org/libros/4/1650/5.pdf> [Consultado 10 de noviembre de 2011].

CAAMAÑo ROJO, Eduardo. "La ley de subcontratación y la tutela de los derechos fundamentales de los trabajadores de servicios transitorios", en: Ius et Praxis, vol. 13, № 2. Talca, Chile: Universidad de Talca, Facultad de Ciencias Jurídicas y Sociales, 2007.

CAAMAÑo ROJO, Eduardo. "La eficacia de los Derechos Fundamentales en las relaciones laborales y su reconocimiento por la Dirección del Trabajo", en: Revista de Derecho (Valparaíso), vol. 1, No XXVII. Valparaíso, Chile: Pontificia Universidad Católica de Valparaíso, 2006.

Gamonal Contreras, Sergio. Procedimiento de Tutela de derechos Laborales. Santiago, Chile: Editorial LexisNexis, 2007.

Gamonal Contreras, Sergio. Ciudadania en la empresa o los derechos fundamentales inespecificos. Montevideo, Uruguay: FCU, 2004.

García Dalmado, Juan Antonio. "El juicio de ponderación y sus partes. Una crítica”. En: VV.AA. Derechos sociales y ponderación. Madrid, España: Fundación Coloquio Europeo, 2007.

García FigueroA, Alfonso. “Ontología y función de los mandatos de optimización”. En: VV.AA. Derechos sociales y ponderación. Madrid, España: Fundación Coloquio Europeo, 2007.

Lopera Mesa, Gloria Patricia. "Los derechos fundamentales como mandatos de optimización”, en: Doxa. Cuadernos de Filosofía del Derecho No 27. Alicante, España: Universidad de Alicante, 2004.

Moreso, Juan José. “Alexy y la aritmética de la ponderación”. En: VV.AA. Derechos sociales y ponderación. Madrid, España: Fundación Coloquio Europeo, 2007.

SERnA, Pedro y TOLLER, Fernando. La interpretación constitucional de los derechos fundamentales. Una alternativa a los conflictos de derecho. Buenos Aires, Argentina: Editorial La Ley, 2000.

UGARTE CATALDO, José Luis. "La constitucionalización del derecho del trabajo: la tutela de derechos fundamentales”, en: Revista Latinoamericana de Derecho Social No 7, julio-diciembre. México: Instituto de Investigaciones Jurídicas, Universidad Nacional Autónoma de México, 2008.

UGARTE CATALDO, José Luis. "La tutela de derechos fundamentales y el derecho del trabajo: de erizo a zorro", en: Revista de Derecho, vol. XX No 2. Valdivia, Chile: Universidad Austral de Chile, Facultad de Ciencias Jurídicas y Sociales, 2007. 
Ugarte Cataldo, José Luis. El Nuevo Derecho del Trabajo. Santiago, Chile: Editorial LexisNexis, 2007.

Ugarte CATAldo, José Luis. Los Derechos Fundamentales del Trabajador: el nuevo procedimiento de tutela laboral. Santiago, Chile: Colección Ensayos Jurídicos, Universidad Alberto Hurtado, No 2, 2006, p. 22.

Ugarte Cataldo, José Luis. "Privacidad, trabajo y derechos fundamentales”, en: Estudios Constitucionales, Año 9, No 1. Talca, Chile: Centro de Estudios Constitucionales de Chile Universidad de Talca, 2001. 